\title{
Chronic oral arsenic intoxication as a possible aetiological factor in idiopathic portal hypertension (non-cirrhotic portal fibrosis) in India
}

\author{
D. V. DATTA, S. K. Mitra, P. N. ChHuttani, AND R. N. CHAKRAVARti \\ From the Division of Hepatic Diseases, Postgraduate Institute of Medical Education and Research, \\ Chandigarh, India
}

SUMMARY Estimates were made of the arsenic concentration in liver specimens from nine patients having idiopathic portal hypertension (IP), and in four livers these were found to be significantly higher than those in patients with cirrhosis and in control subjects. The splenovenogram revealed extensive portosystemic collateral circulation. Corrected sinusoidal pressure and blood flow studies showed higher levels in four patients than in normal subjects. Microscopic examination of liver tissues revealed periportal fibrosis. The higher hepatic arsenic levels that were found were due to the inadvertent drinking of water contaminated with arsenic, adulterated opium, and indigenous medicines. A history of opium intake was not forthcoming but two patients had drunk water contaminated with arsenic and two others had taken bhasams (Ayurvedic medicines prepared by repeated oxidation of ores). Though the aetiology of idiopathic portal hypertension is not known, it is possible that arsenic intake may be one of the factors.

Idiopathic portal hypertension (IP) has recently been recognised as a new entity (Ramalingaswami et al., 1962; Boyer et al., 1967; Basu Mallik et al., 1967; Sama et al., 1971; Datta, 1975; Datta, 1976a). In this condition haematemesis and splenic enlargement are common features, and solenovenographic studies reveal collaterals in $80 \%$ of cases. The aetiology of the syndrome is unknown and it has been suggested that there may be several causes (Datta, 1975; Mahajan and Datta, 1976).

Morris et al. (1974), Huet et al. (1975), and Datta (1976b) reported a relationship between arsenic ingestion and non-cirrhotic portal hypertension. The histological similarity between the liver biopsies of their patients and ours led us to investigate the level of arsenic in the livers of patients with idiopathic portal hypertension. In two of our cases high arsenic levels in the liver were related to drinking water contaminated with arsenic and, in two other cases, to the use of bhasams. Bhasams, Ayurvedic medicines prepared from rocks and minerals, are very commonly used in India by Ayurvedic practitioners and frequently by unqualified village quacks. As bhasams had hitherto not been analysed they were chemically examined and a high percentage of arsenic was found.

Received for publication 27 February 1979

\section{Methods}

\section{SUBJECTS}

The livers of nine patients with idiopathic portal hypertension (IP) and seven with cirrhosis were investigated for their content of arsenic. A piece of liver (about $2 \mathrm{~g}$ ) was obtained by wedge biopsy at laparotomy in six patients and the same quantity from necropsy in three patients. The gross and microscopic examination of 18 patients who showed no evidence of hepatic disease and who died from non-hepatic causes served as controls in our studies. Nine liver tissues were obtained from newborn infants. In addition, 105 livers were obtained through the Department of Forensic Medicine, Postgraduate Institute of Medical Education and Research, Chandigarh, from subjects who died from accidents, and who came from the same area as the patients with IP.

The arsenic content in other organs-that is, heart, kidney, jejunum, aorta, and portal vein-was also estimated at necropsy in one patient who had idiopathic portal hypertension (case 1) and one of the control subjects.

The arsenic content of various bhasams obtained from Ayurvedic practitioners in different villages was estimated by the method of Kingslay and Schaffert (1951). Routine liver function tests were 
carried out by the standard method of King and Wootton (1959). Hepatic vein catheterisation was also carried out in fasting patients premedicated with phenobarbitone. Pressures were recorded with a Cournand catheter no. 7, using a seven-channel electronic recorder and Statham transducer (Datta et al., 1975). All pressure recordings were taken $5 \mathrm{~cm}$ below the sternal angle with the patients lying in the supine position. Hepatic blood flow was estimated by the method of Caesar et al. (1961). Corrected sinusoidal pressure, defined as the difference between wedge pressure and free hepatic vein pressures, was estimated in all patients.

\section{BIOCHEMICAL AND OTHER OBSERVATIONS}

\section{AND CLINICAL RESULTS}

The nine patients with idiopathic portal hypertension all gave a long history of swelling in the left upper quadrant or one or more episodes of haematemesis. Physical examination revealed splenomegaly in all the patients, while splenovenographic examination revealed collateral circulation in eight of nine patients. Pigmentation, hyperkeratosis, and diminished deep reflexes were associated findings in some of these patients (Table 1).

\section{Hepatic arsenic level}

The hepatic arsenic level in nine newborn infants ranged from 0-0.05 $\mathrm{ppm}$ (mean \pm SD 0.0056 $\pm 0.0167)$ and in 18 adult controls from $0-0.20 \mathrm{ppm}$ $(0.071 \pm 0.058)$, while values in the 105 livers obtained from the Department of Forensic Medicine ranged from 0-0.60 ppm. The mean arsenic content in patients with cirrhosis was found to be $0.178 \pm$ 0.171 with a range of $0-0.375 \mathrm{ppm}$. On the other hand, patients with IP showed a range of 0.025-2.47 ppm $(0.887 \pm 0 \cdot 404)$. Statistically, this level was higher than in control subjects $(P<0.01)$ (Fig. 1). It is interesting to note that patients nos 2 and 5, who drank water from a well which was found to have a high arsenic content $(0.549$ and $0.360 \mathrm{ppm})$, had high arsenic concentrations of 2.47 and 0.57

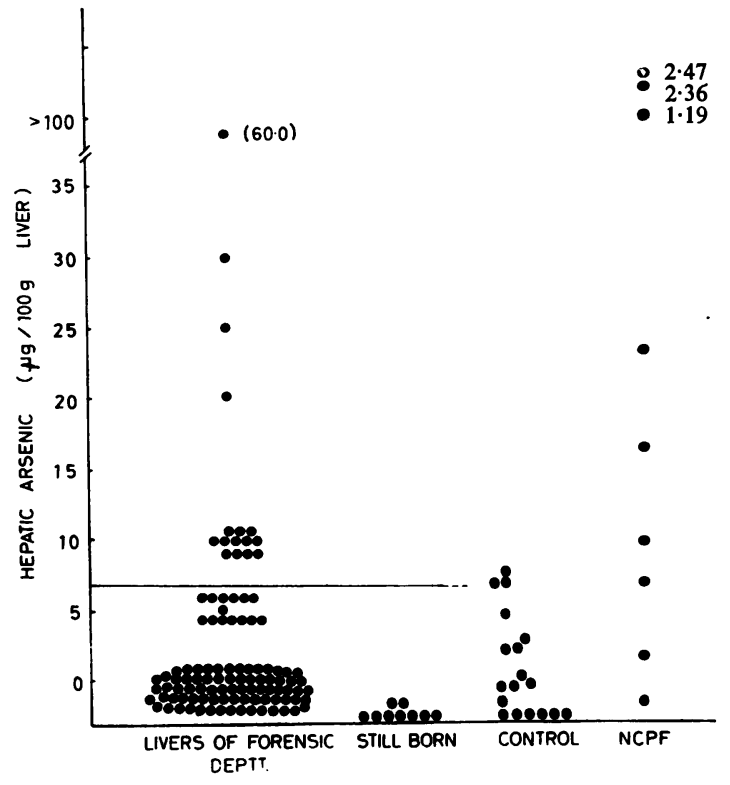

Fig. 1 Hepatic arsenic levels in non-cirrhotic portal fibrosis and control subjects. $(100 \mu \mathrm{g} / 100 \mathrm{~g}$ arsenic $=$ 1 ppm arsenic.)

ppm respectively. Patients nos 1 and 6, who had taken bhasams, had arsenic concentrations of $1 \cdot 19$ and $0.375 \mathrm{ppm}$.

\section{Haemodynamic studies}

The results of haemodynamic studies are shown in Table 2. Intrasplenic pressure was found to be raised in all seven patients in whom it was determined (Table 2). Corrected sinusoidal pressure in five of nine patients was above $5 \mathrm{~mm} \mathrm{Hg}$ (normal $2.3 \pm 1.1 \mathrm{~mm} \mathrm{Hg}$ ) (Datta, 1976a) and it was normal in the rest. Although there was a mild rise of corrected sinusoidal pressure (CSP) in five patients, yet, in all the nine patients with portal hypertension, it was presinusoidal, as the gradient between ISP and CSP was over 17 in all of them. Estimated

Table 1 Clinical features of patients studied

\begin{tabular}{|c|c|c|c|c|c|}
\hline Case no. & Age (yr), sex & Presenting complaints and duration & Spleen size $(\mathrm{cm})$ & Haematemesis & Collaterals on splenovenogram \\
\hline $\begin{array}{l}1 \\
2 \\
3 \\
4 \\
5 \\
6 \\
7 \\
7 \\
8 \\
9\end{array}$ & $\begin{array}{l}36 \mathrm{~F} \\
16 \mathrm{~F} \\
16 \mathrm{M} \\
26 \mathrm{~F} \\
24 \mathrm{~F} \\
30 \mathrm{M} \\
38 \mathrm{M} \\
32 \mathrm{M} \\
19 \mathrm{~F}\end{array}$ & $\begin{array}{l}\text { Pain } R \text { hypo. } 6 \mathrm{~m} \\
\text { Mass L hypo. } 1 \mathrm{yr} \\
\text { Haematemesis, aged } 13 \mathrm{yr} \\
\text { Mass L hypo. } 4 \mathrm{yr} \\
\text { Mass L hypo. } 10 \mathrm{yr} \\
\text { Mass L hypo. } 12 \mathrm{yr} \\
\text { Mass L hypo. } 5 \mathrm{yr} \\
\text { Pain and mass } \mathrm{R} \text { hypo. } 1 \mathrm{yr} \\
\text { Mass L hypo. } 10 \mathrm{yr}\end{array}$ & $\begin{array}{c}7^{*} \\
22 \dagger \\
15^{*} \\
8 \\
12 \\
7 \\
3 \\
13^{*} \\
14\end{array}$ & $\begin{array}{l}\text { Yes } \\
\text { Yes } \\
\text { Yes } \\
\text { No } \\
\text { No } \\
\text { Yes } \\
\text { Yes } \\
\text { No } \\
\text { Yes }\end{array}$ & $\begin{array}{l}+ \\
+ \\
+ \\
- \\
+ \\
+ \\
+ \\
+\end{array}$ \\
\hline
\end{tabular}

Hypo.: hypochrondium. + : present. - : absent.

* 1. Nerve conduction velocity decreased. 2 . Segmental demyelination and loss of myelinated fibres in sural nerve. †Deep tendon reflexes, diminished hyperpigmentation, and hyperkerotosis.

After Samanta et al. (1974). 
Table 2 Results of laboratory tests

\begin{tabular}{|c|c|c|c|c|c|c|c|c|c|}
\hline \multirow[t]{3}{*}{ Case no. } & \multirow{3}{*}{$\begin{array}{l}\text { Liver tissue } \\
\text { arsenic ppm }\end{array}$} & \multicolumn{4}{|c|}{ Biochemical } & \multicolumn{4}{|c|}{ Haemodynamic } \\
\hline & & \multirow[t]{2}{*}{$\begin{array}{l}\text { Bilirubin } \\
(\mu \mathrm{mol} / \mathrm{l})\end{array}$} & \multirow{2}{*}{$\begin{array}{l}\text { Albumin } \\
\text { globulin }(\mathrm{g} / l)\end{array}$} & \multirow{2}{*}{$\begin{array}{l}\text { Alkaline } \\
\text { phosphatase } \\
(K A / d l)\end{array}$} & \multirow{2}{*}{$\begin{array}{l}\text { Intrasplenic } \\
\text { pressure } \\
(\mathrm{mm} \mathrm{Hg})\end{array}$} & \multicolumn{2}{|c|}{$\begin{array}{l}\text { Hepatic vein } \\
\text { pressure }(\mathrm{mm} \mathrm{Hg})\end{array}$} & \multirow{2}{*}{$\begin{array}{l}\text { Corrected } \\
\text { sinusoidal } \\
\text { pressure }\end{array}$} & \multirow{2}{*}{$\begin{array}{l}\text { Hepatic } \\
\text { blood flow } \\
\text { (ml/min) }\end{array}$} \\
\hline & & & & & & Wedge & Free & & \\
\hline $1^{*}$ & $1 \cdot 19$ & 8.6 & $32 / 30$ & $4 \cdot 8$ & 34 & 10.5 & $4 \cdot 3$ & 6.2 & ND \\
\hline $2^{*}$ & $2 \cdot 47$ & $17 \cdot 1$ & $30 / 18$ & $14 \cdot 0$ & 43 & 5.0 & $2 \cdot 5$ & $2 \cdot 5$ & 761 \\
\hline $3^{*}$ & $2 \cdot 36$ & $25 \cdot 7$ & $32 / 35$ & 20.0 & 31 & 12.6 & $7 \cdot 1$ & $5 \cdot 5$ & 1550 \\
\hline $4^{*}$ & 0.03 & 8.6 & $32 / 34$ & $4 \cdot 8$ & 41 & 12.0 & $7 \cdot 0$ & $5 \cdot 0$ & 3000 \\
\hline $5^{*}$ & 0.57 & $12 \cdot 8$ & $30 / 37$ & $20 \cdot 0$ & ND & 9.4 & $7 \cdot 9$ & $1 \cdot 5$ & 990 \\
\hline $6+$ & 0.38 & 8.6 & $33 / 27$ & 8.8 & 41 & $10 \cdot 1$ & $7 \cdot 3$ & $2 \cdot 8$ & 3080 \\
\hline $7 \dagger$ & 0.25 & 8.6 & $19 / 28$ & $3 \cdot 3$ & 30 & $9 \cdot 1$ & 1.7 & $7 \cdot 4$ & 1370 \\
\hline $8^{*}$ & Nil & 8.6 & $29 / 38$ & 12.0 & 27 & $15 \cdot 4$ & $4 \cdot 6$ & $10 \cdot 8$ & 3000 \\
\hline $9^{*}$ & $0 \cdot 10$ & $8 \cdot 6$ & $32 / 36$ & 6.0 & ND & $15 \cdot 0$ & $6 \cdot 0$ & $9 \cdot 0$ & 3800 \\
\hline
\end{tabular}

ND: Not done.

* Tissue obtained at laparotomy.

$\dagger$ Tissue obtained at necropsy.

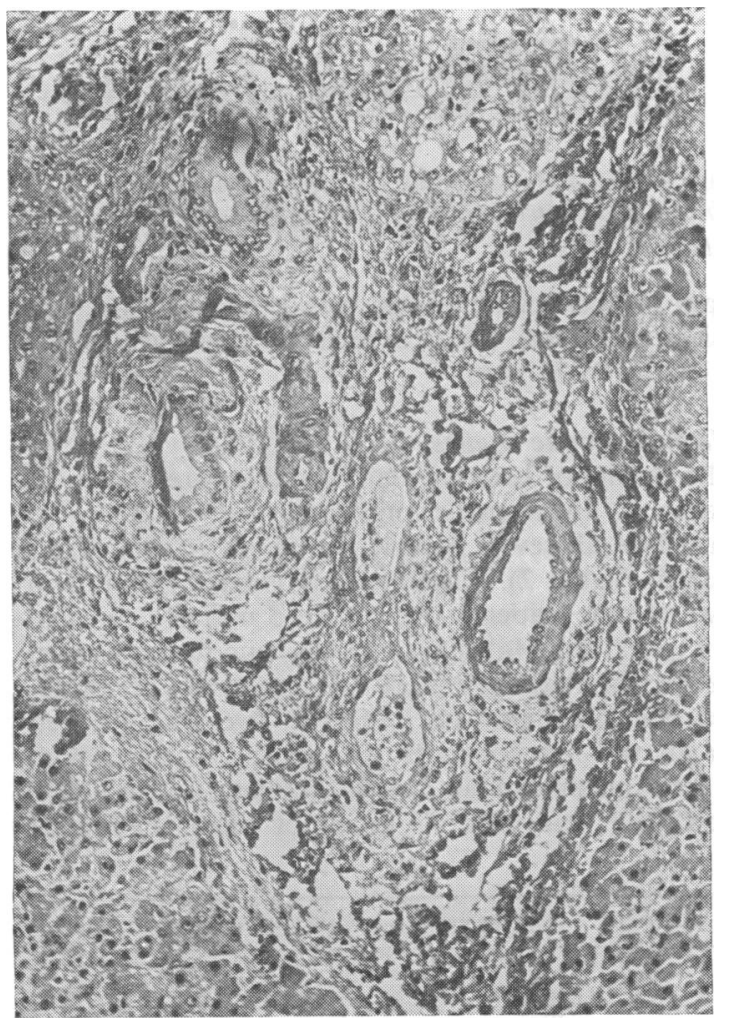

Fig. 2 Section of the liver showing prominent portal tract with increased fibrosis tissue, thickening of the portal vein branches, and a few inflammatory cells. The surrounding cells show mild fatty change. $H$ and $E \times 100$ (original magnification).

hepatic blood flow was found to be very high in five of eight patients studied and was within the normal range in patients with a high arsenic level.
There was no significant correlation between hepatic arsenic and the haemodynamic findings $(P>0.05)$.

\section{Histological studies}

A varying degree of fibrosis was observed in the samples of liver obtained from the Forensic Medicine Department. None of the livers showed portal vein thickening. Portal fibrosis was present in all patients (Fig. 2) with idiopathic portal hypertension. The intrasplenic portal veins were thickened and sclerosed in five of nine patients and a number of portal vein branches were replaced by multiple vascular channels within the liver (Fig. 3). Bile duct proliferation was seen in two patients (nos 8 and 9) and the pathologist concluded that biopsy revealed congenital hepatic fibrosis in case no. 9 and sclerosing cholengitis in case no. 8. It is important to note that these two patients also had a lower hepatic arsenic level. Thus, seven patients fulfilled all the criteria of IP as laid down by the Indian Council of Medical Research (ICMR).

Nerve conduction studies and sural nerve biopsy were carried out in three patients (nos 1, 3, and 8). Nerve conduction velocity was reduced and histology of the sural nerve revealed congenital demyelination and a loss of myelinated fibres.

\section{History of intake of drugs or opium}

It is our impression that significant numbers of farmers and other rural labourers in northern India consume opium adulterated with arsenic (Datta and Kaul, 1977). The history of opium intake is not always reliable, as it is consumed illegally. A previous study showed high arsenic levels in opium samples obtained from unauthorised sellers (Datta, $1977 \mathrm{a}, \mathrm{b})$. In the present study, a history of taking bhasams was available in two patients only. Table 3 


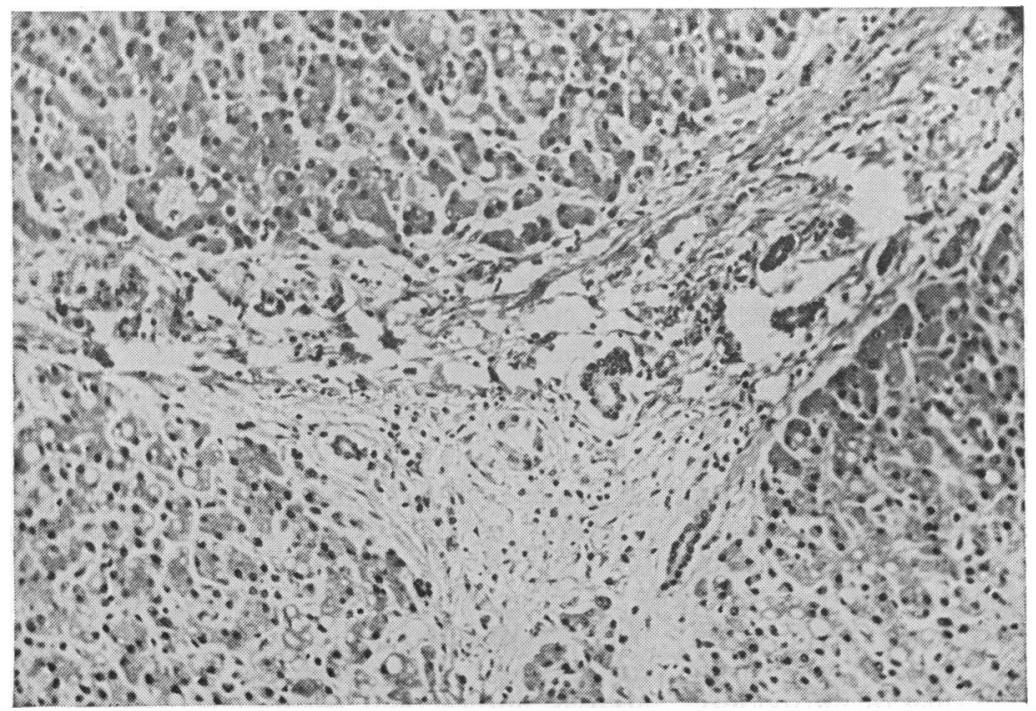

Fig. 3 Section of the liver showing prominent portal tract with replacement of the main intrahepatic vein by small distorted multiple channels. This was a common feature. There is some aggregation of mononuclear inflammatory cells. $H$ and $E \times 40$ (original magnification).

Table 3 Arsenic and copper contents in different bhasams (Ayurvedic medicines)

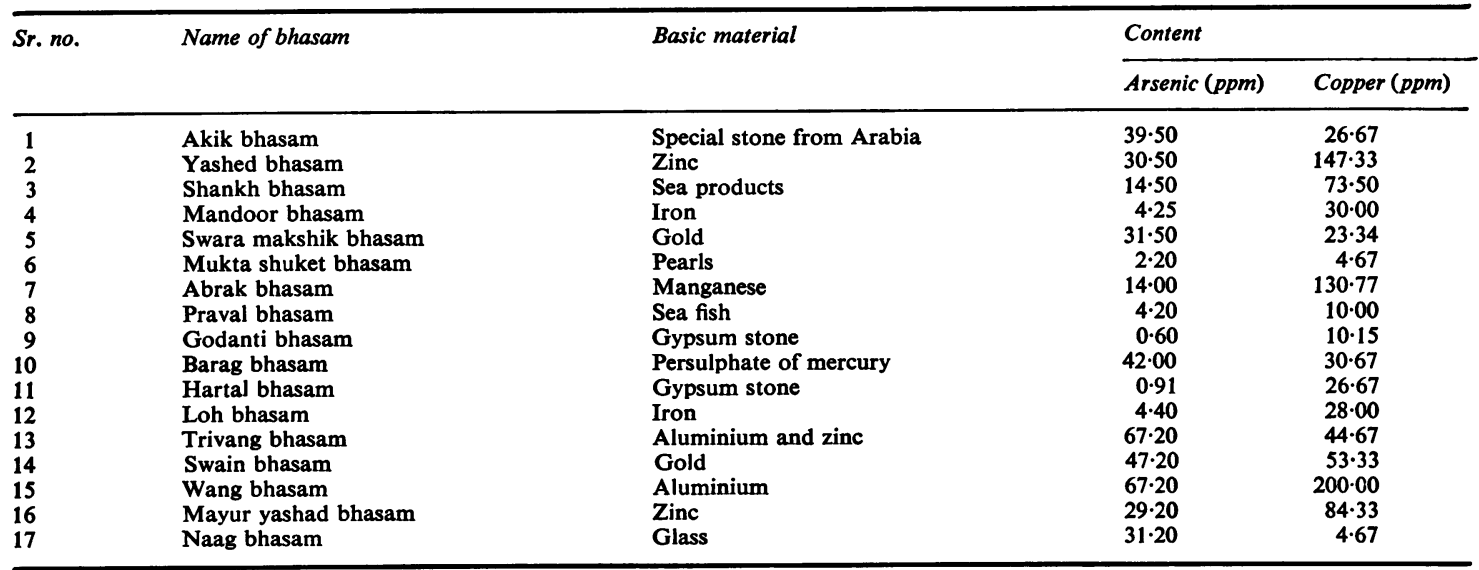

Copper was estimated by the method of Rice (1960).

shows the varying concentrations of arsenic and copper in bhasams in common use.

\section{Clinical history}

J.D., a 15-year-old girl from Kanoda (UP), was admitted to the Division of Hepatology, Postgraduate Institute of Medical Education and Research, Chandigarh, complaining of low grade fever, malaria of recent onset, a mass in the left upper quadrant and discomfort of one year's duration. She denied any past history of umbilical sepsis, haematemesis, malaena, jaundice, or prior episodes of loss of consciousness and pedal oedema. The physical examination revealed splenic enlargement $20 \mathrm{~cm}$ below the costal margin. There was no jaundice, oedema, lymphadenopathy, cachexis, or hepatomegaly.

Liver function tests showed normal bilirubin and alkaline phosphatase levels. Hypoproteinemia was present with an albumin level of $30 \mathrm{~g} / \mathrm{l}$ and a globulin level $18 \mathrm{~g} / \mathrm{l}$. (Table 2). Water from a domestic hand pump that was used for drinking and cooking by this patient and her family was found to have a high concentration of arsenic $(57 \mu \mathrm{g} / 100 \mathrm{ml})$. On the basis of splenoportographic and manometric studies, a presumptive diagnosis of extrahepatic portal vein obstruction was entertained and the patient was subjected to laparotomy. It revealed a patent splenic and portal vein, and a liver surface showing finely granular focal areas. Wedge biopsy 
taken at the time of operation was consistent with the diagnosis of IP (Datta, 1975). Splenectomy was performed to relieve the left upper quadrant discomfort, but she suddenly vomited $500 \mathrm{ml}$ of clotted blood and became hypotensive, comatose, and died seven days after the initial episode.

Necropsy revealed a fresh thrombus in the portal vein. Evidence of IP was seen on histology of the liver and the arsenic concentration of various tissues was found to be raised (Table 4).

It is significant that two other members of this patient's family had gross splenomegaly on physical examination, with normal liver function tests. They refused investigative procedures. Fifty of the other inhabitants in the same village were examined but none of them was found to have gross splenomegaly. Moreover, they denied using water from the well belonging to this patient's family. The determination of arsenic concentration of water from their well demonstrated lower values $(6 \mu \mathrm{g} / 100 \mathrm{ml})$.

\section{Discussion}

The toxic effects of arsenicals have only recently been recognised. Franklin et al. (1950) drew attention to the development of fibrosis and cirrhosis in four patients taking Fowler's solution for therapeutic purposes.

Our studies reveal that, in the monkey, the liver is the main organ in which arsenic is deposited but other organs, such as the kidney, spleen, pancreas, and brain, can also be affected. In fact, arsenic can be found in all tissues of the body if it is fed orally (Datta, in preparation), so that our similar findings in a patient with IP is not surprising.

Rosenberg (1974) observed the presence of intimal thickening in the small and medium sized arteries of four patients (aged 2 to 3 years) at necropsy. All the patients came from North Chile where the arsenic concentration of the water supply has been reported by previous investigators to be as high as $80 \mu \mathrm{g} / 100 \mathrm{ml}$.

The absence of any major disturbance in liver function tests (Table 2) or of any histologically apparent damage of the hepatocyte suggests that such damage does not contribute to this syndrome, when it is precipitated by chronic oral ingestion. This view is supported by the report of Villeneuve et al. (1976), who, despite normal liver function tests, obtained markedly raised intrasplenic pressure in their patients. The absence of any precise correlation between the level of arsenic in the liver and portal venous pressure is noteworthy. Franklin et al. (1950) have suggested the individual tissue's susceptibility to arsenic as a possible explanation. An alternative view may be the special relation of the biopsy sites to the main portal vein system. The presence of periportal cellular infiltration, portal fibrosis, and raised portal vein pressures in the absence of arterial fibrosis and microscopic changes in the hepatocytes lead us to postulate an initial effect of chronic arsenic poisoning on the portal vein subendothelium leading to portal fibrosis.

In this context it is important to note the observation of Morris et al. (1974) and Huet et al. (1975) who have also reported the development of idiopathic portal hypertension after intake of arsenicals.

Northern India is exposed to arsenicals in various ways. It is a common practice for landlords to feed opium obtained from unauthorised sources to their workers in order to increase their output. People, in addition to this, are known to take opium as an aphrodisiac. Opium is often found to be adulterated with arsenic by the vendors (Datta and Kaul, 1977). Further, Ayurvedic medicines, especially bhasams (Datta et al., 1977), and the drinking water of some villages (Datta and Kaul, 1976) have also been shown to contain high levels of arsenic and we can speculate that these may be responsible for the high

Table 4 Arsenic content (ppm) in different tissues in non-cirrhotic portal fibrosis and control subjects

\begin{tabular}{|c|c|c|c|}
\hline & \multicolumn{3}{|l|}{ Age of tissues (years) } \\
\hline & $\begin{array}{l}15 \\
\text { Case of } N C P F^{*}(N o .2)\end{array}$ & $\begin{array}{l}30 \\
\text { Control subject } \dagger\end{array}$ & $\begin{array}{l}\text { Approx. } 3 \\
\text { Case reported by Rosenberg }\end{array}$ \\
\hline Liver & $2 \cdot 47$ & $0 \cdot 10$ & $7 \cdot 40$ \\
\hline Kidney & 1.57 & 0.06 & $7 \cdot 10$ \\
\hline Aorta & $1 \cdot 14$ & ND & $5 \cdot 70$ \\
\hline Brain & 0.40 & 0.06 & $3 \cdot 30$ \\
\hline Portal vein & 0.36 & ND & ND \\
\hline Heart & $2 \cdot 46$ & Nil & $5 \cdot 70$ \\
\hline
\end{tabular}

ND: not done.

* The patient was consuming arsenic rich water.

†Subject died in motor accident. $\ddagger$ Case reported by Rosenberg. 
levels of arsenic observed in our patients.

The arsenic levels in cirrhotic patients deserve comment. Liver biopsy specimens obtained from two patients showed a marginally higher arsenic level but these were comparable with those in livers obtained from the Department of Forensic Medicine. This aspect of the problem needs detailed study to determine whether this trace element plays any part in the pathogenesis of cryptogenic cirrhosis in India. Insecticides containing arsenic have been reported to be a factor in the cirrhosis found in vineyard workers (Lüchtrath, 1972).

The haemodynamic changes deserve special attention. Presinusoidal hypertension can be easily explained, but patients with high levels of arsenic in the liver showed normal liver blood flow, while those with normal hepatic arsenic had increased blood flow. Though increased blood flow is reported in idiopathic portal hypertension (Datta, 1976a), no such blood flow and hepatic arsenic studies are available in the biomedical literature and no definite aetiological explanation can be given at this stage. This once again emphasises the heterogeneous aetiology of this condition (Datta, 1976a). More studies of how arsenic affects the population are indicated. The potential danger of taking such bhasams, the precise composition of which is unknown, is obvious. It is all the more dangerous because these are prescribed indiscriminately by village quacks.

The occurrence of extrahepatic deposition of arsenic has already been reported by Rosenberg (1974) and is not a new finding. It is very possible that arsenic may be responsible not only for hepatic but also for extrahepatic disorders. The extrahepatic manifestations of chronic arsenic ingestion are well known. Peripheral neuropathy is an important clinical syndrome (Chhuttani et al., 1967) and the finding of nerve conduction defects and the reduction of deep reflexes are suggestive of the demyelination seen in patients showing high levels of hepatic arsenic and may be further proof of arsenic poisoning.

The presence of high levels of arsenic in the liver biopsy specimens of patients with idiopathic portal hypertension raises important questions. It is possible that arsenic plays a part in the pathogenesis of this disorder. However, with the data that are available at present, it is not possible to determine whether or not arsenic plays a similar role in the pathogenesis of cryptogenic cirrhosis. From the epidemiological point of view, it is important and establishes the source of arsenic. We have already shown that opium, bhasams, and the village water supply are important sources of arsenic intake in northern India. At present we are engaged in a large scale epidemiological study to examine the exact relationship between chronic liver disorders and the consumption of arsenic in our subcontinent.

ADDENDUM After this paper had been submitted for publication, liver specimens obtained from necropsy of 16 subjects with Indian childhood cirrhosis (ICC) were biochemically analysed for their arsenic content. The arsenic level was $0 \cdot 744 \pm 0.218$ ppm against the four controls of $0.047 \pm 0.047 \mathrm{ppm}$ $(\mathrm{P}<0.001)$. In 15 liver samples of ICC arsenic and copper were estimated by the neutron activation method at Trombay. The liver arsenic was $0 \cdot 178 \pm$ $0.048 \mathrm{ppm}$ and copper was $605.929 \pm 331.343 \mathrm{ppm}$. Arsenic and copper in six adult controls was 0.019 \pm $0.003 \mathrm{ppm}$ and $58.116 \pm 2.449 \mathrm{ppm}$, respectively. The arsenic and copper levels in ICC were highly significant when compared with controls $(\mathrm{P}<0.0001)$. These observations lead us to conclude that copper and arsenic may play a significant role in the pathogenesis of ICC. It is possible that this is the result of the common Indian custom of consuming bhasams.

The authors are grateful to Professor B. K. Aikat, Professor I. J. Dewan, Dr A. G. Bhaqwat and Dr J. S. Chopra for help in various stages of the study, especially in relation to nerve conduction studies, and to Professor I. J. Dewan, Professor M. Losowsky, Leeds University, and Dr Frank Apantaku, North Western Memorial Hospital, Chicago, for critical comments and editorial advice. Shri Baldev Raj Chaudhry, Shri Haqiqat Singh, and Shri V. P. Madan are acknowledged for their technical assistance. Dr B. S. Anand, Dr M. S. Khuroo, and A. P. S. Narang gave their time in studying the manuscript. We are grateful to Shri Jatinder Singh for help in editing the manuscript. DVD would like to thank Professor Dame Sheila Sherlock for help and encouragement.

\section{References}

Basu Mallik, K. C., Sen Gupta, K. P., Basu, A. K., Biswas, S. K., Pal, N. C., and Boyer, J. (1967). Non-cirrhotic portal fibrosis with portal hypertension: a new syndrome. Indian Journal of Medical Research, 55, 351-359.

Boyer, J. L., Sen Gupta, K. P., Biswas, S. K., Pal, N. C., Basu Mallik, K. C., Iber, F. L., and Basu, A. K. (1967). Idiopathic portal hypertension. Annals of Internal Medicine, 66, 41-68.

Caesar, J., Shaldon, S., Chiandussi, L., Guevara, L., and Sherlock, S. (1961). The use of Indocyanine green in the measurement of hepatic blood flow and as a test of hepatic function. Clinical Science, 21, 43-57.

Chhuttani, P. N., Chawla, L. S., and Sharma, T. D. (1967). Arsenical neuropathy. Neurology, 17, 269-274.

Datta, D. V. (1975). Tropical Gastroenterology. Edited by 
Dr S. J. Baker. Indian Books Trust Publication: New Delhi.

Datta, D. V. (1976a). Non-cirrhotic portal fibrosis ('Idiopathic' portal hypertension in India). Journal of the Association of Physicians of India, 24, 511-527.

Datta, D. V. (1976b), Arsenic and non-cirrhotic portal hypertension (Letter). Lancet, 1, 433.

Datta, D. V. (1977b). Arsenic in opium (Letter). Lancet, 1, 903-904.

Datta, D. V. (1977a). Arsenic in opium. Lancet, 1, 484.

Datta, D. V., and Kaul, M. K. (1976). Arsenic content in drinking water in villages in Northern India. A concept of arsenicosis. Journal of the Association of Physicians of India, 24, 599-604.

Datta, D. V., and Kaul, M. K. (1977). Arsenic adulteration in opium. Bulletin of Narcotics, 29 (3), 41-44.

Datta, D. V., Narang, A. P. S., and Chhuttani, P. N. (1977). Arsenic concentration in Ayurvedic medicines. In Proceedings of 18th Meeting of Indian Society of Gastroenterology held at Manipal.

Datta, D. V., Grover, S. L., Saini, V. K., Datta, B. N., Aikat, B. K., and Chhuttani, P. N. (1975). Portal hypertension in chronic leukaemia. British Journal of Haematology, 31, 279-285.

Franklin, M., Bean, W. B., and Hardin, R. C. (1950). Fowler's solution as aetiologic agent in cirrhosis. American Journal of Medical Science, 219, 589-596.

Huet, P. M., Guillaume, E., Côté, J., Légaré, A., Lavoie, P., and Viallet, A. (1975). Noncirrhotic presinusoidal portal hypertension associated with chronic arsenical intoxication. Gastroenterology, 68, 1270-1277.

King, E. J., and Wootton, I. D. P. (1959). Microanalysis in Medical Biochemistry. Churchill: London.

Kingslay, G. R., and Schaffert, R. R. (1951). Microdeter- mination of arsenic and its application to biological material. Analytical Chemistry, 23, 914-928.

Lüchtrath, H. (1972). Cirrhosis of the liver in chronic arsenical poisoning of vintners. German Medicine, 2, 127-128.

Mahajan, R. C., and Datta, D. V. (1976). Malarial antibody studies in non-cirrhotic portal fibrosis-a preliminary observation. Indian Journal of Medical Research, 64, 652-655.

Morris, J. S., Schmid, M., Newman, S., Schever, P. J., and Sherlock S. (1974). Arsenic and noncirrhotic portal hypertension. Gastroenterology, 66, 86-94.

Ramalingaswami, V., Wig, K. L., and Sama, S. K. (1962). Cirrhosis of the liver in northern India. Archives oj Internal Medicine, 110, 350-358.

Rice, E. W. (1960). Spectrophotometric determination of serum copper with oxalyldihyrazide. Journal of Laboratory and Clinical Medicine, 55, 325-326.

Rosenberg, H. G. (1974). Systemic arterial disease and chronic arsenicism in infants. Archives of Pathology, 97, 360-365.

Sama, S. K., Bhargava, S., Gopi Nath, N., Talwar, J. R., Nayak, N. C., Tandon, B. N., and Wig, K. L. (1971). Non-cirrhotic portal fibrosis. American Journal of Medicine, 51, 160-169.

Samanta, A. K. S., Sawknery, B. B., Chopra, J. S., and Datta, D. V. (1974). Peripheral neuropathy in non-alcoholic cirrhosis and non-cirrhotic portal fibrosis. In Proceedings of the Second Liver Study Group held at Varanari.

Villeneuve, J. P., Huet, P. M., Joly, J. G., Marleau, D., Coté, J., Légaré, A., Lafortune, M., Lavoie, P., and Viallet, A. (1976). Idiopathic portal hypertension. American Journal of Medicine, 61, 459-464. 